Research Paper

\title{
CPG-C ODN M362 as an immunoadjuvant for HBV therapeutic vaccine reverses the systemic tolerance against $\mathrm{HBV}$
}

\author{
Huajun Zhao, Qiuju Han, Ailu Yang, Yucan Wang, Guan Wang, Ang Lin, Xiao Wang, Chunlai Yin, Jian \\ Zhang ${ }^{\circledR}$ \\ Institute of Immunopharmaceutical Sciences, School of Pharmaceutical Sciences, Shandong University, Jinan, China. \\ $\triangle$ Corresponding author: Jian Zhang, Ph.D., Institute of Immunopharmaceutical Sciences, School of Pharmaceutical Sciences, Shandong University, No. 44 \\ Wenhua West Road, Jinan, Shandong, 250012, China; E-mail: zhangj65@sdu.edu.cn; Tel: 86-531-8838-3781; Fax: 86-531-8838-3782. \\ () The author(s). This is an open access article distributed under the terms of the Creative Commons Attribution License (https://creativecommons.org/licenses/by/4.0/). \\ See http://ivyspring.com/terms for full terms and conditions.
}

Received: 2021.05.07; Accepted: 2021.10.20; Published: 2022.01.01

\begin{abstract}
Chronic Hepatitis B virus (CHB) infection is a global public health problem. Oligodeoxynucleotides (ODNs) containing class $C$ unmethylated cytosine-guanine dinucleotide (CpG-C) motifs may provide potential adjuvants for the immunotherapeutic strategy against $\mathrm{CHB}$, since $\mathrm{CpG}-\mathrm{C}$ ODNs stimulate both $B$ cell and dendritic cell (DC) activation. However, the efficacy of CpG-C ODN as an anti-HBV vaccine adjuvant remains unclear. In this study, we demonstrated that CpG M362 (CpG-C ODN) as an adjuvant in anti-HBV vaccine (cHBV-vaccine) successfully and safely eliminated the virus in HBV-carrier mice. The cHBV-vaccine enhanced DC maturation both in vivo and in vitro, overcame immune tolerance, and recovered exhausted T cells in HBV-carrier mice. Furthermore, the cHBV-vaccine elicited robust hepatic $\mathrm{HBV}$-specific $\mathrm{CD}^{+}$and $\mathrm{CD} 4{ }^{+} \mathrm{T}$ cell responses, with increased cellular proliferation and IFN-y secretion. Additionally, the $\mathrm{cHBV}$-vaccine invoked a long-lasting follicular CXCR5 ${ }^{+} \mathrm{CD} 8^{+} \mathrm{T}$ cell response following $\mathrm{HBV}$ re-challenge. Taken together, CpG M362 in combination with rHBVvac cleared persistent HBV and achieved long-term virological control, making it a promising candidate for treating CHB.
\end{abstract}

Key words: chronic hepatitis B, CpG-C ODN, therapeutic vaccine, adjuvant, immune-tolerance, CXCR5 $5^{+} \mathrm{CD} 8^{+} \mathrm{T}$ cells

\section{Introduction}

Chronic Hepatitis B virus (CHB) infection currently affects approximately 240 million people worldwide [1]. Patients with CHB are at higher risk for developing cirrhosis and hepatocellular carcinoma (HCC) [2]. Current antiviral therapies, such as pegylated interferon alpha2a (PegIFN) and nucleoside/nucleotide analogues (NAs), are unable to achieve efficient hepatitis B surface antigen (HBsAg) loss [3]. Therefore, a novel strategy involving immunomodulation needs to be developed to achieve long-term virological control in CHB.

The pathological basis of $\mathrm{CHB}$ infection is the persistent presence of $\mathrm{HBV}$ covalently closed circular DNA (cccDNA) in the nuclei of infected hepatocytes, as well as an immunosuppressive environment in the infected liver [4,5]. Both the innate and adaptive immune responses are involved in the pathogenesis of $\mathrm{CHB}$ infection, and influence its clinical outcome [5-7]. However, HBV-specific immune responses are characteristically weak, transient and nearly undetectable in $\mathrm{CHB}$ patients. Furthermore, neither the prophylactic $\mathrm{HBV}$ vaccine alone nor its combination with other antiviral compounds has successfully eliminated HBV-infected cells in CHB. Since the ideal HBV therapy should reverse host immune tolerance to the virus and recover the function of HBV-specific T cells, an effective adjuvant may improve the success of therapeutic $\mathrm{HBV}$ vaccines.

CpG oligodeoxynucleotide (CpG ODN) are synthetic single-stranded DNA molecules containing unmethylated cytosine-guanine dinucleotide (CpG) 
motifs. As an agonist for Toll-like receptor 9 (TLR9), immuno-stimulatory CpG activates antigenpresenting cells (APCs) to produce inflammatory cytokines, thus inducing the $\mathrm{T}$ helper type 1 (Th1)-type immune response via TLR9 activation [8-10]. At least three major classes of CpG-ODNs have been characterized according to their backbone, sequence, and immuno-stimulatory properties: class A (D-type), class B (K-type), and class C [11]. CpG-A ODNs such as CpG 1585, CpG 2216, and CpG 2336 activate plasmacytoid dendritic cells (pDCs) to produce interferon- $\alpha$ (IFN- $\alpha$ ), but fail to induce B cell activation $[8,9]$. In contrast, CpG-B ODNs such as CpG 1826, CpG 2006, and CpG 7909 strongly induce B cells to produce interleukin-6 (IL-6), but promote pDC maturation with absence of IFN-a secretion [8, 12]. Finally, CpG-C ODNs combine the features of classes $\mathrm{A}$ and $\mathrm{B}$, activating both pDCs and B cells [13]. CpG ODNs have been widely used as adjuvants for various antiviral vaccines against hepatitis $\mathrm{C}$ virus $(\mathrm{HCV})$, human immunodeficiency virus (HIV), and HBV, as well as cancer cells [14-16]. The prophylactic HBV vaccine Engerix-B combined with CpG 7909 (CpG-B ODN) resulted in higher $\mathrm{HBs}$ antibody (anti-HBs) titers and enhanced affinity maturation to improve the avidity of anti-HBs [16]. In addition, a two-dose schedule of HEPLISAV-B, comprised of recombinant HBsAg and 1018 ISS (CpG-B ODN), demonstrated a significantly higher rate of protection $(95 \%)$ compared to that observed with Engerix-B (81\%) in a phase III trial $[17,18]$. Systemic administration of CpG 1826 (CpG-B ODN) inhibited HBV replication by inducing type I IFNs in HBV transgenic mice $[19,20]$. In another study, administration of nanoparticles containing unmethylated CpG-A ODNs (HBV-CpG) exerted a strong immuno-stimulatory effect on DCs, NK cells, and $\mathrm{T}$ cells in vivo, and led to viral clearance in HBV-carrier mice [21]. Taken together, these studies indicate that $\mathrm{CpG}-\mathrm{A}$ and $-\mathrm{B}$ agonists may function as potent immunomodulatory agents against $\mathrm{CHB}$ infection by augmenting HBV-specific $\mathrm{T}$ or $\mathrm{B}$ cell responses. In a phase $1 \mathrm{~b}$ multicenter trial, $\mathrm{CpG} 10101$ (CpG-C ODN) activated the immune response along with secretion of IFN- $\alpha$ to reduce HCV RNA levels in a dose-dependent manner [22]. Furthermore, intra-tumoral SD-101 (CpG-C ODN) administration in combination with low-dose radiation in a phase $1 / 2$ trial promoted the generation of tumor-specific CD8 ${ }^{+}$ and $\mathrm{CD}^{+}$effector T-cells, and reduced the abundance of $\mathrm{T}$ regulatory cells (Tregs) in the tumor microenvironment, which in turn led to complete tumor regression in both treated and untreated tumor sites [23]. However, the therapeutic utility of CpG-C ODNs as HBV vaccine adjuvants remains unclear.

Exhausted $\mathrm{CD}^{+} \mathrm{T}$ cells play a critical role in the development of CHB infection. Recent studies have reported that CXCR5-expressing $\mathrm{CD}^{+} \mathrm{T}$ cells are partially exhausted with strong antiviral activity [24-27], producing higher levels of IFN- $\gamma$, TNF- $\alpha$, IL-21, and granzymes during lymphocytic choriomeningitis virus (LCMV), HIV, and other chronic infections than CXCR5 ${ }^{-} \mathrm{CD}^{+} \mathrm{T}$ cells. Additionally, CXCR5 ${ }^{+} \mathrm{CD} 8^{+} \mathrm{T}$ cells can migrate into B cell follicles, thereby supporting B cell activation, affinity maturation, and antibody production [26-28]. CXC chemokine ligand 13 (CXCL13) exclusively binds to chemokine receptor CXCR5 expressed on CD8 ${ }^{+} \mathrm{T}$ cells to help recruit $\mathrm{CXCR5}^{+} \mathrm{T}$ cells to the inflammatory site, thus coordinating both humoral and cellular immune responses [29,30]. Moreover, $\mathrm{Li}$ et al. reported that elevated expression of CXCL13 facilitated the recruitment of CXCR5 ${ }^{+} \mathrm{CD} 8{ }^{+} \mathrm{T}$ cells in the liver, which in turn inhibited HBV replication and regulated production of $\mathrm{B}$ cell antibodies in patients with CHB [27]. However, whether CpG-C ODNs can sustain HBV control by inducing the follicular $\mathrm{CXCR}^{+} \mathrm{CD}^{+} \mathrm{T}$ cell response is unknown.

Previous studies have demonstrated that an $\mathrm{HBV}$-carrier mouse model of persistent HBV infection can be generated via injection of an AAV-HBV vector [31-34]. These mice do not mount the specific immune response to conventional HBV vaccines, thus mimicking the immune tolerance exhibited in human CHB [32, 33, 35]. Therefore, the goal of the current study was to evaluate the therapeutic feasibility of using CpG-C ODN M362 as an HBV vaccine adjuvant using $\mathrm{AAV} / \mathrm{HBV}$-transduced $\mathrm{HBV}$-carrier mice.

\section{Materials and Methods}

\section{Animals and reagents}

Five- to six-week-old male C57BL/6J mice were purchased from the Beijing HFK Bioscience Co. Ltd (Beijing, China). All animals were treated in accordance with the Guidelines for the Care and Use of Laboratory Animals of the Ethical Committee of Shandong University and the protocol was approved by the Institutional Animal Care and Use Committee of Shandong University. rHBVvac (Hansenula polymorpha) was purchased from Dalian Hissen Bio-pharm. Co., Ltd. (Dalian, China) and CpG M362 was obtained from Invivogen (San Diego, CA, USA).

\section{HBV-carrier mouse model}

$\mathrm{HBV}$-carrier mice were generated by AAV-HBV transduction using pAAV/HBV1.2 plasmids carrying full-length HBV DNA (kindly provided by Pei-Jer Chen, National Taiwan University, Taiwan), as previously described [22,32,35,36]. Serum HBsAg levels were measured 6 weeks after hydrodynamic injection of pAAV/HBV1.2 plasmids, and 
HBV-carrier mice were identified as those with serum HBsAg levels > $500 \mathrm{ng} / \mathrm{mL}(1000 \mathrm{ng} / \mathrm{mL}=1.14$ $\mathrm{IU} / \mathrm{mL}$ ).

\section{Vaccination and $\mathrm{HBV}$ re-challenge}

As shown in Fig. 1A, HBV-carrier mice were immunized subcutaneously with phosphate-buffered saline (PBS) (Untr), $2 \mu \mathrm{g}$ rHBV vaccine (rHBVvac), or $2 \mu \mathrm{g}$ rHBVvac combined with $10 \mu \mathrm{g}$ CpG M362 (cHBV-vaccine) weekly for 3 weeks (on days 1, 8, and 15). Blood samples were drawn weekly from the lateral tail vein, and the serum was stored at $-80{ }^{\circ} \mathrm{C}$ until further analysis. For the long-term memory immune response assay, HBV-carrier mice were re-challenged with hydrodynamic injections of $8 \mu \mathrm{g}$ pAAV/HBV1.2 plasmid on day 59 after the first vaccination.

\section{Generation and stimulation of bone marrow-derived dendritic cells (BMDCs) in vitro}

Murine BMDCs were generated as previously described [37], and CD11 $\mathrm{c}^{+}$BMDCs were identified and enriched using fluorescence-activated cell sorting (FACS) (> 90\%). To assess their antigen-presenting ability, the isolated BMDCs were incubated with CpG M362 for $12 \mathrm{~h}$, and surface expression of CD86 and MHC-II was analyzed by flow cytometry.

\section{Chemiluminescent immunoassay (CLIA) and Enzyme-linked immunosorbent assay (ELISA)}

Specific ELISA kits for serum HBsAg (Autobio, Zhengzhou, China), HBeAg (Autobio), anti-HB (Wantai Biological Pharmacy Enterprise Co., Ltd., Beijing, China), and TGF- $\beta 1$ (Multi Sciences Biotech Co., Ltd., Hangzhou, China) were used according to the manufacturers' instructions. Serum alanine aminotransferase (ALT) levels were determined using a commercially available assay kit (Nanjing Jiancheng Bioengineering Institute, Nanjing, China).

\section{HBV DNA detection}

HBV DNA was extracted from $50 \mu \mathrm{L}$ mouse serum using the HBV DNA quantitation kit according to the manufacturer's instructions (Daan Gene, Guangzhou, China) and measured by quantitative PCR using UltraSYBR Mixture (CW Biotech, Beijing, China) with a Lightcycler ${ }^{\circledR} 96$ (Roche, Basel, Switzerland).

\section{Immunohistochemistry (IHC)}

Intrahepatic $\mathrm{HBcAg}$ and $\mathrm{HBsAg}$ were detected in mouse liver sections by immunostaining with anti-HBcAg mAb (\#GB058604, Gene Tech Co., Ltd., Shanghai, China) and anti-HBs mAb (\#GB058604, Gene Tech Co., Ltd.), respectively. Horseradish peroxidase-conjugated goat anti-mouse IgG (\#ZB-2305, ZSGB-bio Co. Ltd, Beijing, China) was used according to the manufacturer's instructions. $\mathrm{HBcAg}^{+}$and $\mathrm{HBsAg}^{+}$hepatocytes were counted using Image-Pro Plus software (Media Cybernetics, Rockville, MD, USA).

\section{Cell isolation}

Single-cell suspensions from the liver, spleen, and draining lymph nodes (dLNs) were isolated as previously described [36]. Briefly, the PBS-perfused liver was passed through a 200- $\mu$ m nylon cell strainer to obtain the single-cell suspension, which was centrifuged at $100 \times \mathrm{rcf}$ for $1 \mathrm{~min}$ to remove hepatocytes. Then, the supernatant was centrifuged at $400 \times$ rcf for $10 \mathrm{~min}$ to collect residual cells, which were layered over 40\% Percoll (GE Healthcare, Uppsala, Sweden). Hepatic mononuclear cells (MNCs) were harvested after centrifugation at $400 \times$ rcf for $10 \mathrm{~min}$, followed by red blood cell (RBC) lysis and washing. The spleens and dLNs were passed through a 200- $\mu \mathrm{m}$ nylon cell strainer, single cells were harvested, followed by RBC lysis, and washing.

\section{Flow cytometry}

Single-cell suspensions were pre-incubated with Fc-receptor blocking solution (anti-mouse CD16/32, \#14-0161-82, eBioscience, California, USA) for $30 \mathrm{~min}$, and stained with the fluorochrome-conjugated antibodies conjugates at $4^{\circ} \mathrm{C}$ for at least $1 \mathrm{~h}$. The following $\mathrm{mAb}$ were used: FITC-anti-CD4 (\#4313007), FITC-anti-CD8a (\#4271604), FITC-anti-CD11c (\#E00155-1631), PE-anti-CD69 (\#E01333-1634), PE-anti-CD8a (\#E01038-1633), PE-anti-CD86 (\#E01369-1634), PE-anti-CD107a (\# E01430-1632), PE-anti-B7H1 (\#4276913), PE-anti-CD49d (\#E01278-1635), PE-anti-CXCR5 (\#E16203-104), PercpCy5.5-anti-CD3e (\#4304569), Percp-Cy5.5-anti-FOXP3 (\#E08398-1634), APC-anti-CD25 (\#E07106-1634), APC-anti-CD80 (\#4329685), APC-anti-PD-1 (\#4344425), eFluor 450-anti-Ki-67 (\#1928649), eFluor 450-mouse hematopoietic lineage (\#2324728) from eBioscience (California, USA); PE-anti-MHC-II (\#107608), Percp-Cy5.5-anti-CD11a (\#101124), BV421-anti-LAG3 (\#125221), PE-Cy7-anti-TIGIT (\#142107), AF700-anti-mouse CD317 (\#127037), APC-Cy7-anti-CD107a (\#121615) from Biolegend (San Diego, USA); PE-CF594-anti-CD8a (\#562283), BV510-anti-CD11a (\#563669) from BD Bioscience (Bedford, USA). All data were acquired on BD FACS Calibur, BD FACS Celesta or BD FACS Aria III flow cytometer and analyzed with FlowJo software (BD Life Sciences, Franklin Lakes, NJ, USA). 


\section{Statistical analysis}

Data were analyzed using GraphPad Prism version 6 software (GraphPad Software, La Jolla, CA, USA) and groups were compared using unpaired two-tailed t-tests and two-way analysis of variance (ANOVA). A p-value $<0.05$ was considered statistically significant $\left({ }^{*} \mathrm{p}<0.05,{ }^{* *} \mathrm{p}<0.01,{ }^{* * *} \mathrm{p}<\right.$ $\left.0.001,{ }^{* * * *} \mathrm{p}<0.0001\right)$.

\section{Results}

\section{cHBV-vaccine efficiently eliminated HBV in carrier mice}

HBV-carrier mice were used to evaluate the efficiency and safety of the cHBV-vaccine (Fig. 1A). The results confirmed that rHBVvac alone did not eliminate HBV (Fig. S1A-C). Compared to serum $\mathrm{HBsAg}$ and $\mathrm{HBeAg}$ levels in untreated mice, those in cHBV-vaccinated mice decreased significantly and remained at low levels after the third immunization (Fig. 1B, 1C). Furthermore, serum HBV DNA, and intrahepatic $\mathrm{HBsAg}$ and $\mathrm{HBcAg}$ were nearly undetectable in cHBV-vaccinated mice (Fig. 1D-F). However, none of these treatments induced the generation of anti-HBs (Fig. S1C). In addition, the serum ALT remained at baseline levels, indicating that $\mathrm{cHBV}$ vaccination did not result in liver injury (Fig. 1G). Taken together, these results indicated that CpG M362 is a promising and safe adjuvant for use in $\mathrm{HBV}$ therapeutic vaccines.

\section{CpG M362 promoted the maturation and antigen-presenting ability of DCs}

As professional APCs, DCs play a vital role in generating antigen-specific $\mathrm{T}$-cell responses against chronic HBV infection [38]. As shown in Fig. 2A-C, the spleen of cHBV-vaccinated mice exhibited higher proportions of myeloid DCs (mDCs) $\left(\mathrm{Lin}^{-/-} \mathrm{MHCII}^{+}\right.$

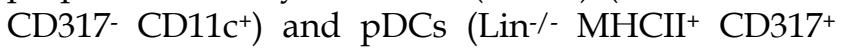
CD11 $\left.c^{\text {int }}\right)$ compared to those in untreated mice. Moreover, the expression of co-stimulatory molecules CD80, CD86, and CD40 was upregulated on mDCs and pDCs in spleen following treatment with the cHBV-vaccine compared to that in untreated mice (Fig. 2D, 2E). A similar phenomenon was observed on mDCs and pDCs in dLNs (Fig. S2A-D). However, treatment with rHBVvac alone did not efficiently enhance DC activation (Fig. 2B-E, Fig. S2A-D). To further confirm the stimulatory effect of $\mathrm{CpG}$ M362 on DCs, BMDCs were generated in vitro and treated with different doses of CpG M362. Consistently, CpG M362 increased the surface expression of MHC-II and CD86 on BMDCs compared to that in the unstimulated controls (Fig. 2F). These results confirmed that the CpG M362 adjuvant promoted the maturation and antigen-presenting ability of DCs in vivo and in vitro.

\section{cHBV-vaccine amplified robust Ag-specific $\mathrm{CD8}^{+}$and $\mathrm{CD4}^{+} \mathrm{T}$ cell responses}

Since $\mathrm{HBV}$-specific $\mathrm{CD} 8^{+}$and $\mathrm{CD} 4^{+} \mathrm{T}$ cells play a crucial role in controlling HBV progression [35, 39], we evaluated whether vaccination enhanced the magnitude and quality of $\mathrm{HBV}$-specific $\mathrm{CD}^{+}$and $\mathrm{CD}^{+} \mathrm{T}$ cell responses. As shown in Fig. 3A and 3B, cHBV-vaccinated mice exhibited a significantly higher proportion of HBV-specific CD11a ${ }^{\text {hi }}$ CD8 ${ }^{\text {lo }}$ cells [35, $36,40]$ in their peripheral blood, liver, and spleen, compared to untreated mice. Furthermore, cHBV-vaccination resulted in a marked increase in the expression of CD69 and CD107a on CD8 ${ }^{+} \mathrm{T}$ cells (Fig. $3 C)$, along with increased IFN- $\gamma$ secretion (Fig. 3D). In addition, the abundance of $\mathrm{HBV}$-specific $\mathrm{CD}^{+}$ CD11a ${ }^{\text {hi }}$ CD49d ${ }^{\text {hi }} \mathrm{CD}^{+} \mathrm{T}$ cells $[35,41]$ was also significantly higher in the spleens of cHBV-vaccinated mice than that in untreated mice (Fig. 3E, 3F), along with increased expression levels of the activation antigen CD69 on $\mathrm{CD}^{+} \mathrm{T}$ cells (Fig. 3G). Taken together, these results indicated that CpG M362, as a vaccine adjuvant, enhanced $\mathrm{HBV}$-specific cellular responses.

\section{cHBV-vaccine alleviated immunosuppression and restored the exhausted HBV-specific CXCR5+ CD8+ $T$ cells}

The immunosuppressive environment and exhaustion of $\mathrm{CD}^{+} \mathrm{T}$ cells in the HBV-infected liver are the major causes underlying the refractoriness of $\mathrm{CHB}[5,39,42]$. cHBV-vaccination downregulated the expression of PD-L1 on hepatocytes of HBV-carrier mice (Fig. 4A), reduced the proportion of Tregs (Fig. $4 \mathrm{~B})$, and decreased TGF- $\beta 1$ levels in liver tissues and serum (Fig. 4C). Furthermore, HBV-specific CD11ahi CD8a a $^{\text {lo }} \mathrm{T}$ cells in $\mathrm{cHBV}$-vaccinated mice displayed significantly reduced expression of LAG-3, CTLA-4, TIGIT, and PD-1 compared to that in untreated mice (Fig. 4D), accompanied by upregulation of pro-proliferative nuclear antigen Ki-67 (Fig. 4E). Follicular $\mathrm{CXCR}^{+} \mathrm{CD} 8^{+} \mathrm{T}$ cells have been recently found to play a pivotal role in controlling viral replication during chronic infections such as HIV, LCMV, and HBV [24, 27]. Interestingly, approximately $5 \%$ of the HBV-specific CD11ahi CD8 $\alpha^{\text {lo }}$ cells in the spleens of HBV-carrier mice abundantly expressed CXCR5. However, the subset of $\mathrm{CXCR}^{+} \mathrm{HBV}$-specific CD11a ${ }^{\text {hi }} \mathrm{CD} 8 \alpha^{\text {lo }}$ cells was more exhausted than the predominant CXCR5- subset (Figure S3). Although the frequency and abundance of CXCR5 ${ }^{+} \mathrm{CD} 11 \mathrm{a}^{\text {hi }} \mathrm{CD} 8 \mathrm{a}^{\text {lo }}$ cells were not significantly altered by cHBV vaccination (Fig. 4F, 4G), the expression of multiple co-inhibitory receptors such as 
LAG-3, PD-1, TIGIT, and TIM-3 was significantly downregulated (Fig. 4H). Meanwhile, cHBV vaccination did not significantly affect the frequency of $\mathrm{CXCR}^{+} \mathrm{CD}^{+} \mathrm{T}$ cells, but decreased the expression of TIGIT and PD-1 on CXCR5 ${ }^{+}$CD11ahi CD4 ${ }^{+}$T cells
(Fig. S4). These results indicated that CpG M362 as a vaccine adjuvant was able to overcome the mechanisms that impaired the functional immune responses in $\mathrm{HBV}$-carrier mice.
A

(a) PBS-alone group (Untr)

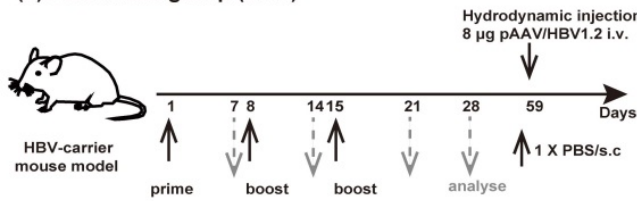

(c) CpG M362 + rHBVvac group (cHBV-vaccine)

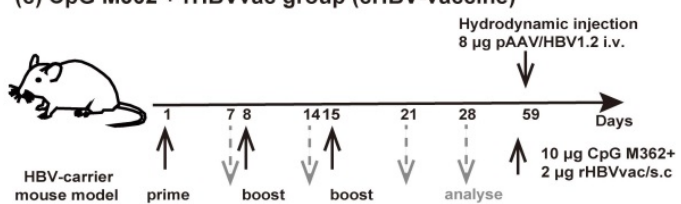

(b) rHBVvac group (rHBVvac)

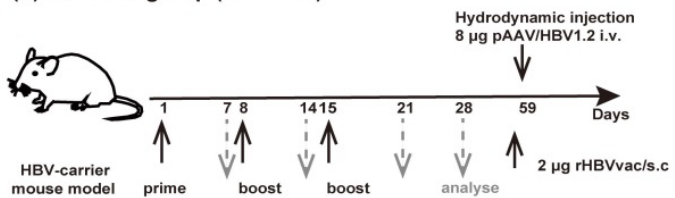

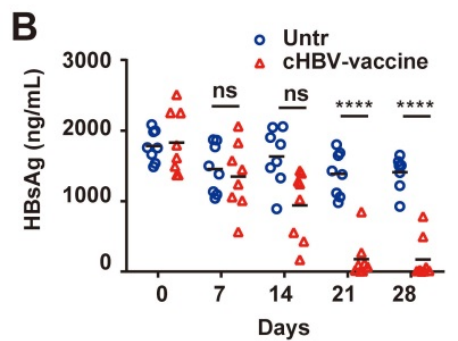

C
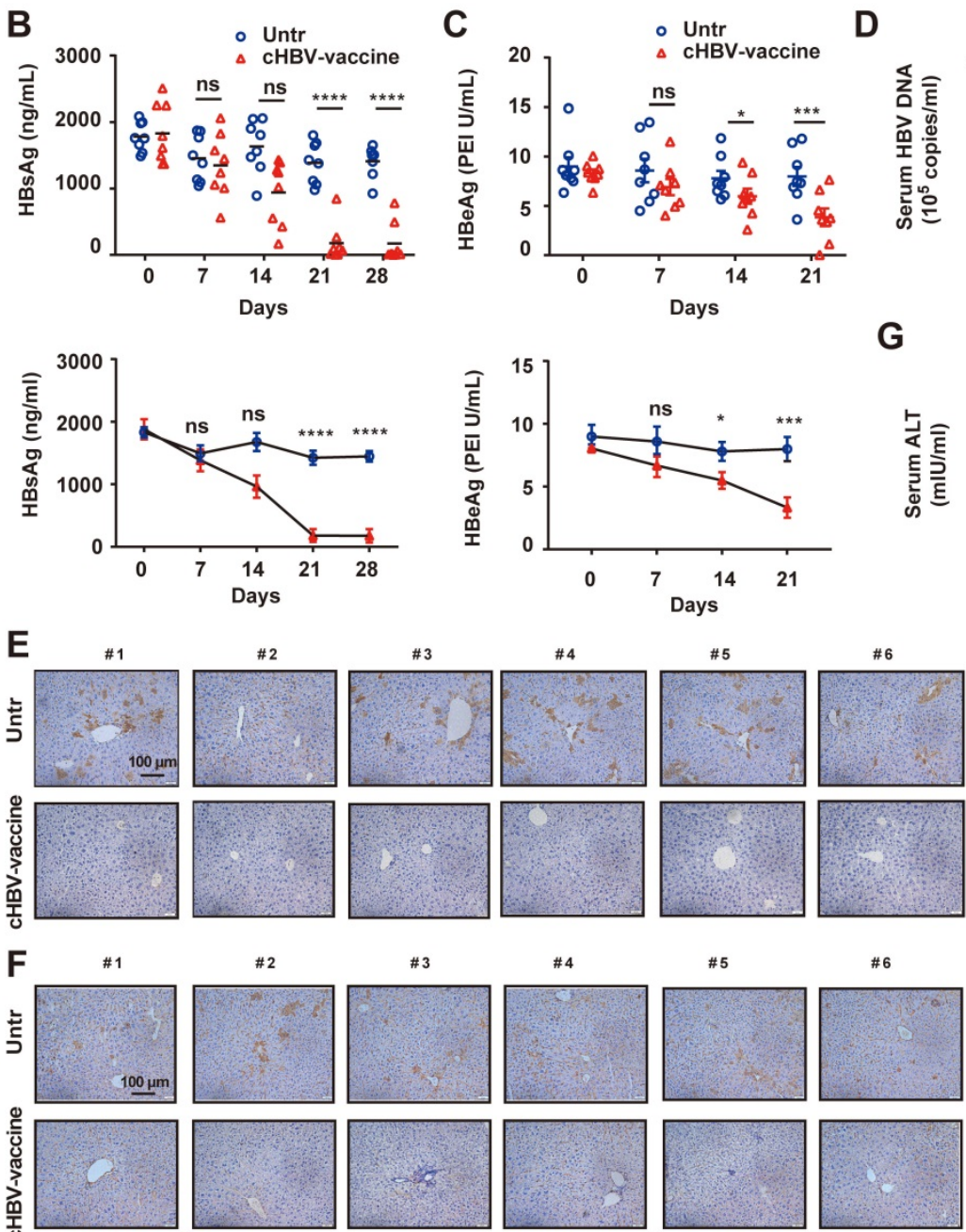

$\mathbf{G}$

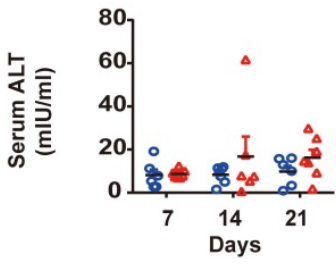

Figure 1. Immunization with cHBV-vaccine efficiently eliminated HBV in the carrier mice. Schematic illustration of HBV vaccination protocol in HBV-carrier mice. Mice were immunized subcutaneously with PBS (Untr), $2 \mu \mathrm{g}$ rHBV vaccine (rHBVvac), or $2 \mu \mathrm{g}$ rHBVvac combined with $10 \mu \mathrm{g}$ CpG M362 (cHBV-vaccine) weekly for 3 weeks (on days 1,8 , and 15). Blood samples were drawn weekly from the lateral tail vein. For the long-term memory immune response assay, HBV-carrier mice were re-challenged with hydrodynamic injections of $8 \mu \mathrm{g}$ PAAV/HBV1.2 plasmid on day 59 after the first vaccination. (B) Post-immunization serum levels of HBsAg, measured by ELISA and compared with two-way ANOVA. (C) Post-immunization serum levels of HBeAg, measured by ELISA and compared with two-way ANOVA. (D) Number of HBV DNA copies on day 21 post-immunization. (E) HBsAg expression in hepatocytes on day 21 post-immunization via IHC staining $(200 \times$ magnification). (F) HBcAg expression in hepatocytes on day 21 post-immunization via IHC staining ( $200 \times$ magnification). (G) Serum levels of ALT monitored on days 7,14 , and 21 post-immunization. (Normal serum ALT levels are $<40$ $\mathrm{mlU} / \mathrm{mL})$. All data are expressed as mean \pm SEM of biological replicates. $* p<0.05, * * p<0.01, * * * p<0.001, * * * * p<0.0001$ versus untreated mice. 
A

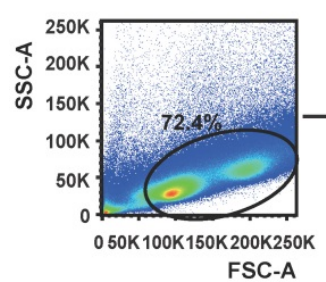

B

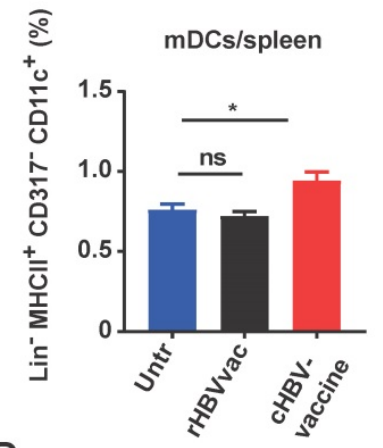

D

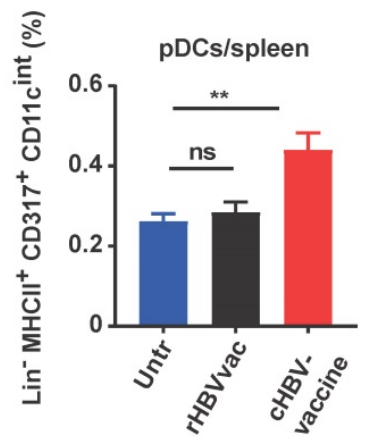

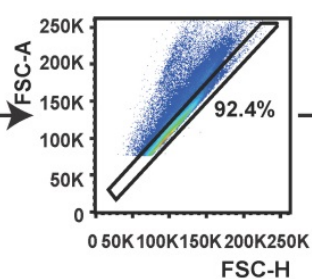

C

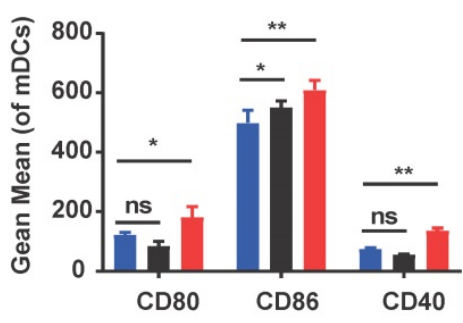

E

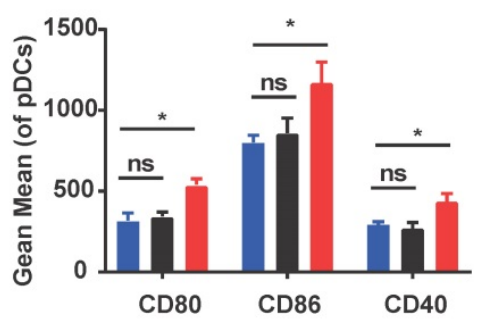

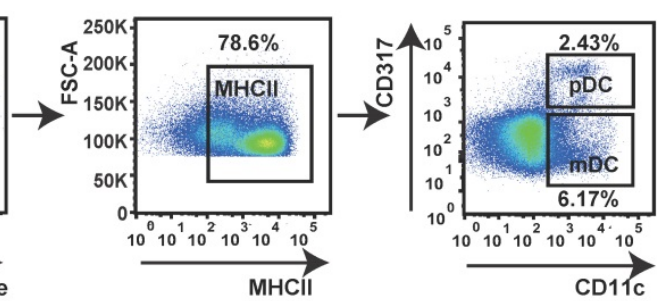

- Untr

- rHBVvac

- cHBV-vaccine
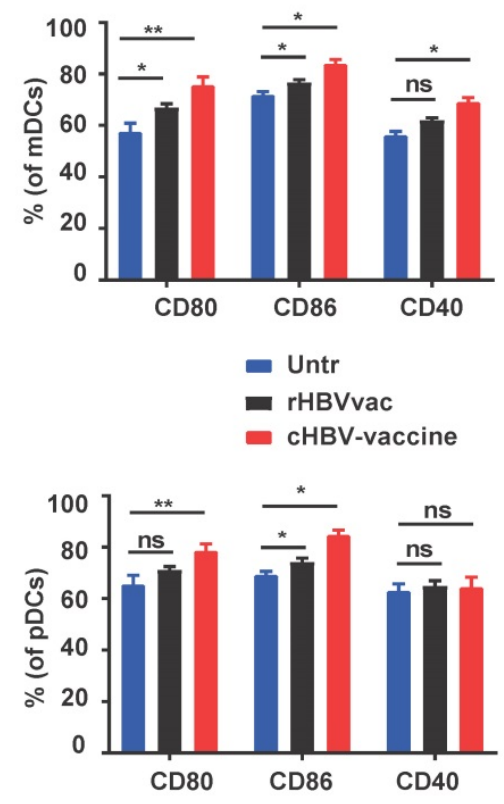

F
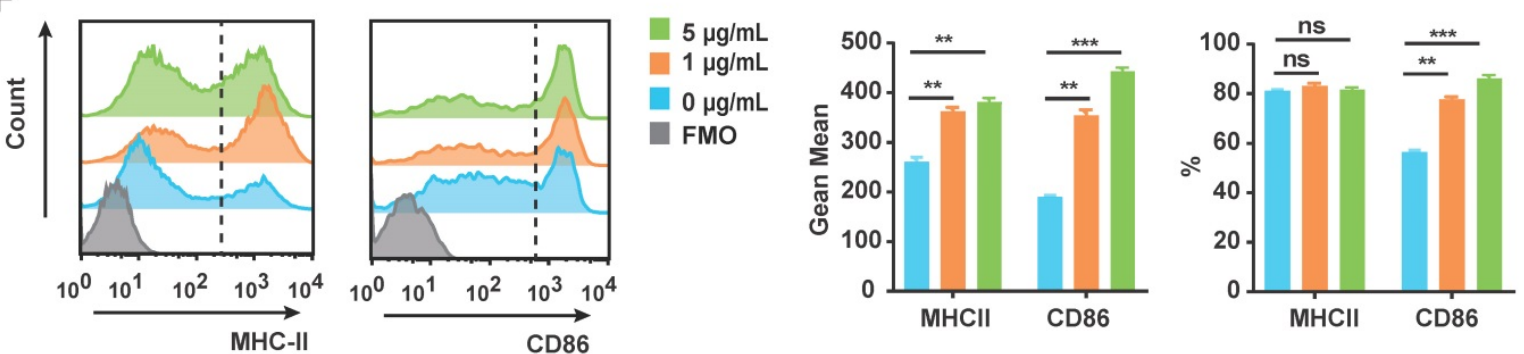

Figure 2. CpG M362 promoted the maturation and antigen presenting ability of DCs. HBV-carrier mice were immunized subcutaneously with PBS (Untr) and $2 \mu g$ rHBVvac combined $10 \mu \mathrm{g}$ CpG M362 (cHBV-vaccine) weekly for 3 weeks, separately. (A) The gating strategy of mDCs and pDCs. (B) Proportion of splenic mDCs (Lin ${ }^{-/-}$MHCII+ CD317- $\left.C D 11 c^{+}\right)$on day 21 post-immunization. (C) Flow cytometry results showing expression of CD80, CD86, and CD40 on splenic mDCs. (D) Proportion of splenic pDCs (Lin $\left.{ }^{-1-} \mathrm{MHCll}^{+} \mathrm{CD} 317^{+} \mathrm{CD} 11 \mathrm{cint}\right)$ on day 21 post-immunization. (E) Flow cytometry results showing expression of CD80, CD86, and CD40 on splenic pDCs. (F) MHC-II and CD86 expression on BMDCs incubated with different doses of CPG M362 for 12 h. All data are expressed as mean $\pm S E M(n \geq 8)$. $* p<0.05$, ** $p<0.01$ versus untreated mice.

\section{cHBV-vaccine induced long-term immune memory against $\mathrm{HBV}$ re-challenge}

The major challenge of clinical HBV therapy is to prolong the immunological memory against the recurrence of $\mathrm{HBV}$ infection [43, 44]. To this end, $\mathrm{HBV}$-carrier mice were re-challenged with $\mathrm{HBV}$ on day 59 after $\mathrm{CHBV}$ vaccination. Both $\mathrm{HBsAg}$ and $\mathrm{HBV}$ DNA were nearly undetectable in the serum of cHBV-vaccinated mice (Fig. 5A, 5B) compared to that in untreated mice, accompanied by higher levels of protective anti-HBs (Fig. 5C). Furthermore, the proportion of $\mathrm{CXCR}^{+}{ }^{+} \mathrm{PD}-1^{+}$follicular helper $\mathrm{T}$ cells increased upon HBV re-challenge (Fig. 5D). Meanwhile, serum ALT remained at the baseline levels in cHBV-vaccinated mice after HBV re-challenge (Fig. S5). Taken together, the results suggested that CpG M362 as a vaccine adjuvant induced long-term immune memory against $\mathrm{HBV}$ re-infection. 
A

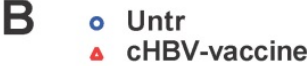

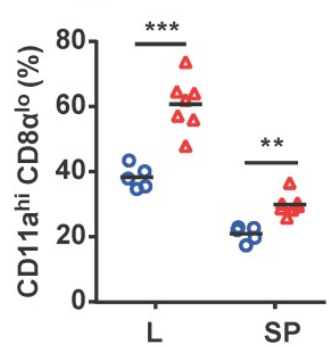

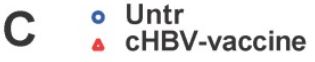
dLN

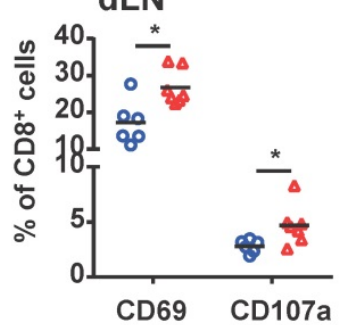

cHBV-vaccine

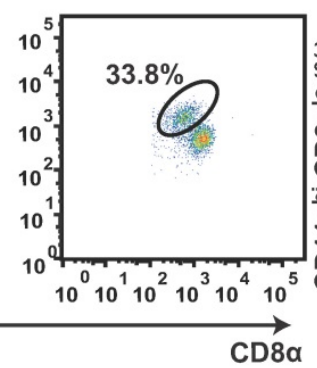

○ Untr

$\triangle$ cHBV-vaccine

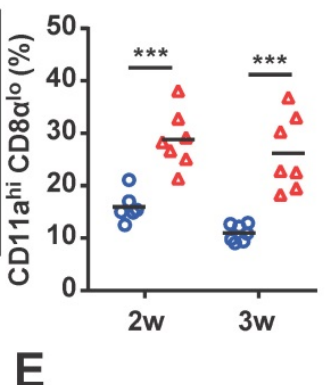

Untr
D
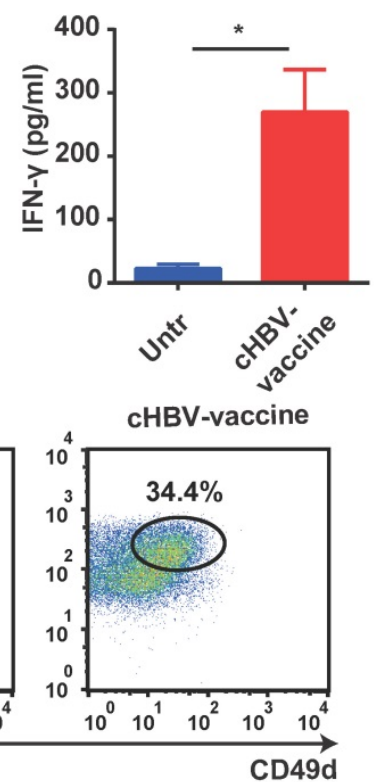

$\mathbf{G}$
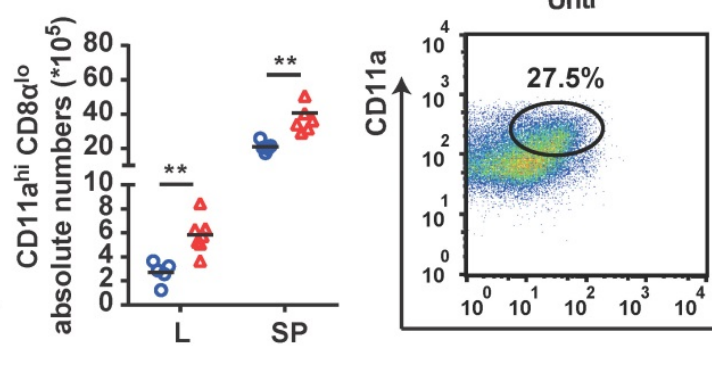

$\mathbf{F}$
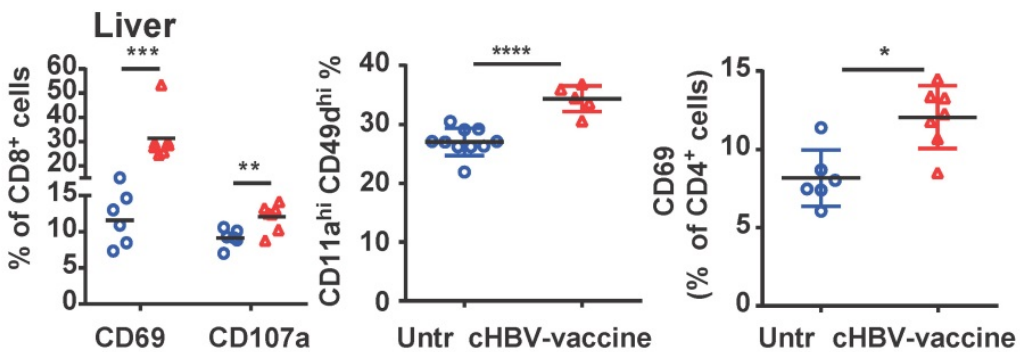

Figure 3. cHBV-vaccine amplified HBV-specific CD8 ${ }^{+} \mathbf{T}$ and $\mathrm{CD4}^{+} \mathbf{T}$ cell responses. HBV-carrier mice were immunized subcutaneously with PBS (Untr) and $2 \mu \mathrm{gg}$

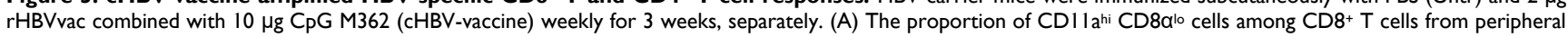
blood. (B) The proportion and abundance of CD1 lahi CD8alo cells among CD8 ${ }^{+} T$ cells from the liver and spleen on day 21 post-immunization. (C) The frequency of CD8 ${ }^{+}$CD69+ $T$ cells and $C D 8^{+} \mathrm{CD} 107 \mathrm{a}^{+} \mathrm{T}$ cells in dLNs (left) and liver (right) on day 21 post-immunization. (D) Serum levels of IFN- $\gamma$ monitored by ELISA on day 21 post-immunization. (E-G) The proportion of $C D 4^{+} \mathrm{CD} 1 \mathrm{lahi} C D 49 \mathrm{dhi}^{\mathrm{T}} \mathrm{cells}(\mathrm{E}, \mathrm{F})$ and $\mathrm{CD} 4^{+} \mathrm{CD} 69^{+} \mathrm{T}$ cells $(\mathrm{G})$ in the spleen on day 21 post-immunization. All data are expressed as mean $\pm \mathrm{SEM}(\mathrm{n} \geq 5)$. $* p<0.05, * * p<0.01, * * * p<0.001, * * * * p<0.0001$ versus untreated mice.

\section{cHBV-vaccine induced long-lasting CXCR5+ $\mathrm{CD8}^{+} \mathrm{T}$ cell response during HBV re-challenge}

An effective vaccine should generate appreciable numbers of high-quality memory $\mathrm{CD}^{+} \mathrm{T}$ cells that can be immediately activated upon re-exposure to the pathogen [45-47]. Compared to untreated mice, the abundance of HBV-specific CD11a ${ }^{\text {hi }}$ CD8 ${ }^{\text {lo }}$ cells in the liver and spleen of cHBV-vaccinated mice increased significantly after HBV re-challenge (Fig. 6A), accompanied by downregulated expression of PD-1 and LAG-3, indicating an effective immune response (Fig. 6B). Furthermore, cHBV vaccination significantly increased the frequency of splenic

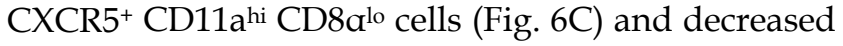
the expression of multiple co-inhibitory receptors (Fig. 6D). Although the frequency of splenic CXCR5 ${ }^{+}$ $\mathrm{CD} 11 \mathrm{a}^{\text {hi }} \mathrm{CD}^{+} \mathrm{T}$ cells increased in response to HBV re-challenge, cHBV vaccination only decreased PD-1 levels on $\mathrm{CXCR}^{+} \mathrm{CD} 11 \mathrm{a}^{\text {hi }} \mathrm{CD} 4^{+} \mathrm{T}$ cells (Fig. S6). These data indicated that the adjuvant properties of CpG M362 induced a long-lasting antiviral CXCR5 ${ }^{+}$ $\mathrm{CD}^{+} \mathrm{T}$ cell response against $\mathrm{HBV}$.

\section{Discussion}

$\mathrm{CHB}$ infection results from a dynamic balance between viral replication and the host immune response. Liver-induced systemic immune tolerance is the basis of $\mathrm{CHB}$, which is characterized by high viral load and impaired $\mathrm{HBV}$-specific adaptive $\mathrm{T}$ cell responses [5, 39]. The ideal endpoints of HBV treatment are HBsAg loss, seroconversion to anti-HBs, and sustained inhibition of HBV DNA [48]. Since HBV antigens are weakly immunogenic, adjuvants are needed to accelerate, prolong, and enhance the immune response against CHB. Among the TLR9 agonists tested as adjuvants in vaccines against cancer cells and intracellular pathogens, CpG ODNs induce 
activation of both the Th1-polarized immune response, including NK cells, macrophages, and APCs, and the humoral immune response to control local tumor growth $[22,49,50]$. Studies have shown that $\mathrm{CHB}$ impairs the host innate immune system by downregulating TLR expression and inhibiting downstream signaling pathways [51, 52]. Meanwhile, treatment with synthetic TLR9 agonists, such as class
A and B CpG ODNs, reportedly enhanced anti-HBV immunity and HBV elimination during CHB therapy $[10,19,21]$. Therefore, the current study investigated the effectiveness of CpG M362, a class C CpG ODN that combines the features of both class $\mathrm{A}$ and $\mathrm{B} C \mathrm{CpG}$ ODNs, as an adjuvant with rHBVvac in HBV-carrier mice.
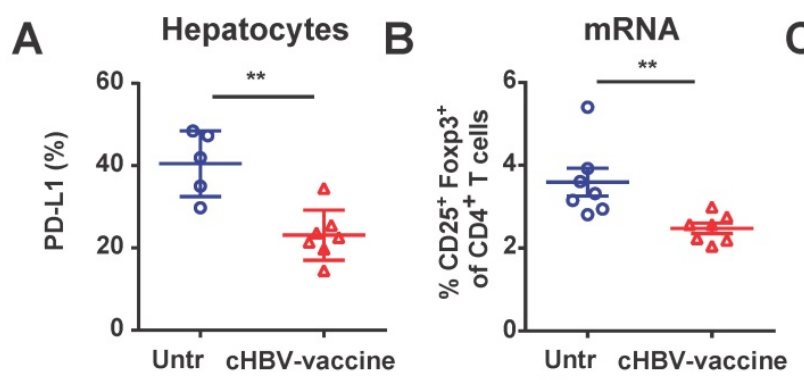

D

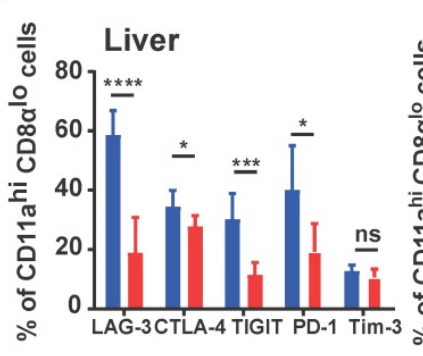

$\mathbf{F}$
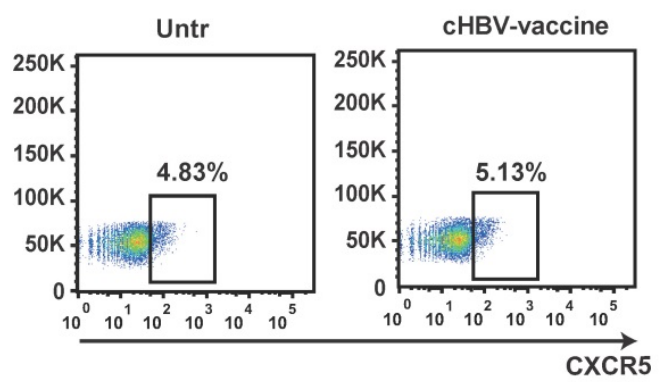

$\mathrm{H}$
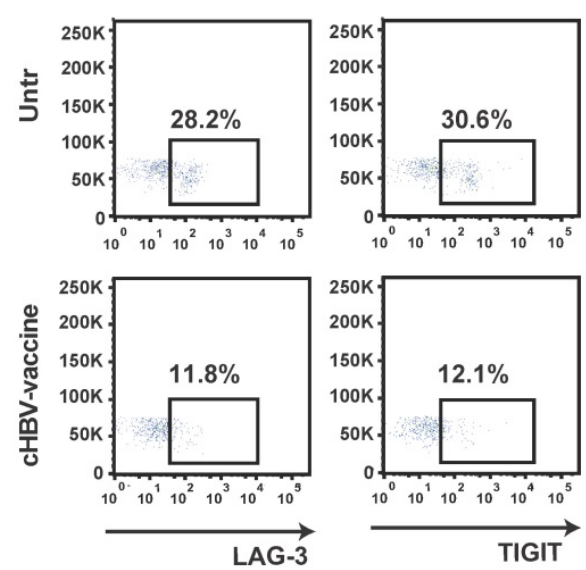
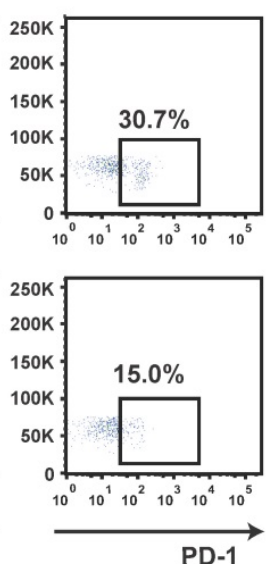
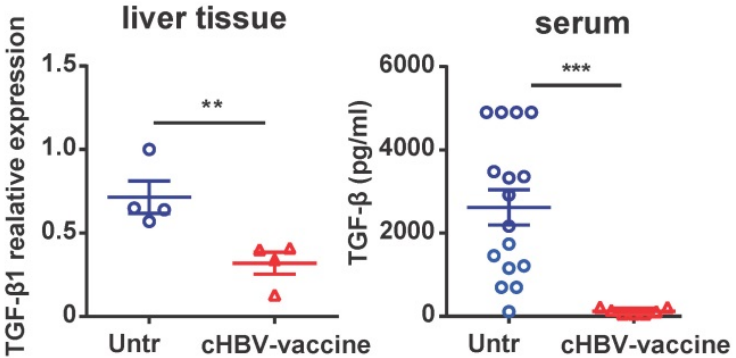

E
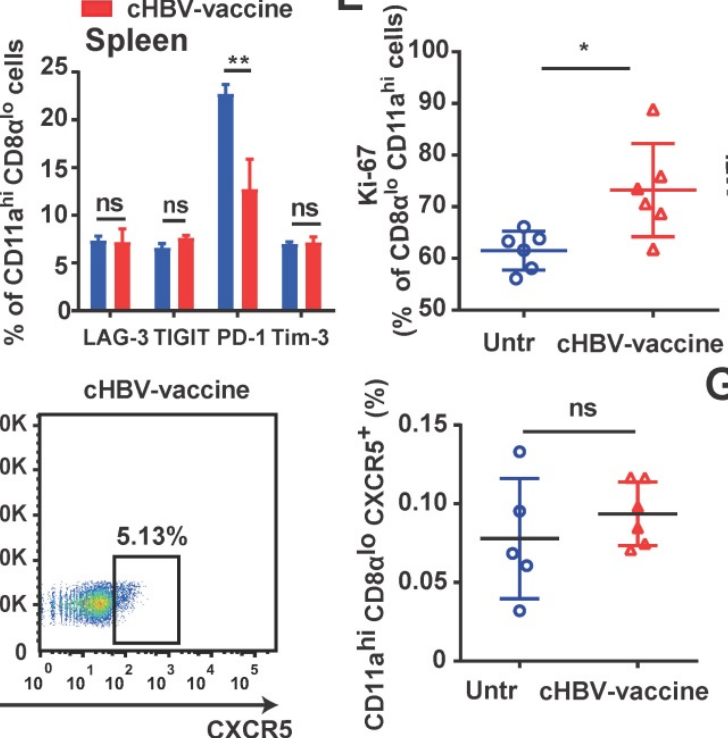

G

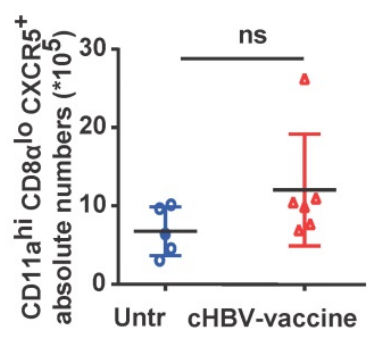

Figure 4. cHBV-vaccine alleviated immunosuppression and restored exhausted HBV-specific $\mathbf{C X C R 5}^{+} \mathrm{CDB}^{+} \mathbf{T}_{\text {cells. }} \mathrm{HBV}$-carrier mice were immunized subcutaneously with PBS (Untr) and $2 \mu \mathrm{g} \mathrm{rHBV}$ vac combined with $10 \mu \mathrm{g}$ CPG M362 (cHBV-vaccine) weekly for 3 weeks, separately. (A) The expression of PD-L1 on hepatocytes on day 21 post-immunization. (B) The proportion of splenic CD4+ $C D 25^{+}$Foxp $3^{+}$on day 21 post-immunization. (C) Relative expression of TGF- $\beta 1$ mRNA in liver tissue and serum TGF- $\beta 1$ levels on day 21 post-immunization. (D) LAG-3, CTLA-4, TIGIT, PD-1 and Tim-3 expression on HBV-specific CD 1 lahi CD8 $\alpha$ lo cells in liver (left) and spleen (right)

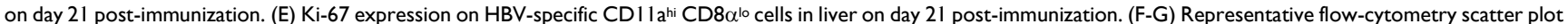
of splenic CXCR5+ CD11 a hi CD8alo $T$ cells. The frequency $(F)$ and abundance $(G)$ of $C X C R 5^{+} C D 11$ ahi $C D 8 a^{l o} T$ cells on day 21 post-immunization. (H) Representative flow-cytometry scatter plot of PD-1, TIGIT, Tim-3, and LAG-3 expression on HBV-specific CXCR5+ CD1 1 a hi CD8alo T cells on day 21 post-immunization. All data are expressed as mean $\pm \operatorname{SEM}(\mathrm{n} \geq 5) . * p<0.05, * * p<0.01, * * * p<0.001$ versus untreated mice. 

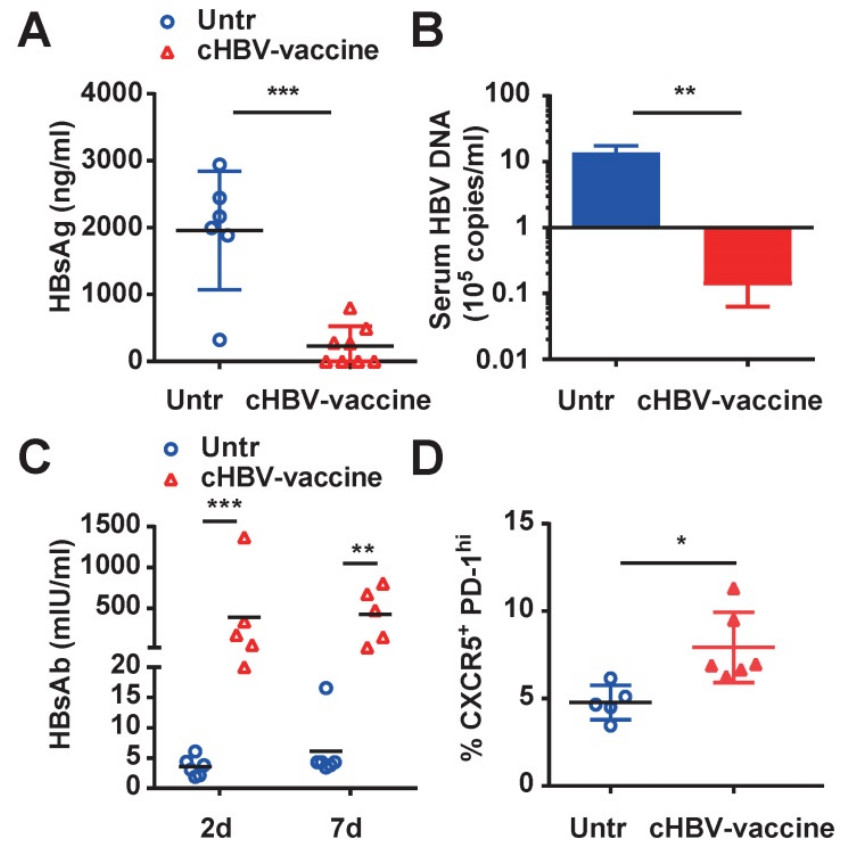

Figure 5. cHBV-vaccine induced long-term immune memory against HBV re-challenge. HBV-carrier mice were immunized subcutaneously with PBS (Untr) and $2 \mu \mathrm{g}$ rHBVvac combined with $10 \mu \mathrm{g}$ CPG M362 (cHBV-vaccine) weekly for 3 weeks, separately. Then, these treated mice were re-challenged with hydrodynamic injection of $8 \mu \mathrm{g}$ PAAV/HBV1.2 plasmid on day 59 after the first vaccination. Serum levels of $\mathrm{HBsAg}(\mathrm{A})$ and $\mathrm{HBV}$ DNA copies (B) detected by CLIA and $q-P C R$ respectively on day 7 after HBV re-challenge. (C) Serum HBsAb levels on day 7 after HBV re-challenge. (D) The frequency of CXCR5+ PD-1+CD4+ $T$ cells ( $T_{\text {fh }}$ cells) in spleen on day 7 after HBV re-challenge. All data are expressed as mean $\pm \operatorname{SEM}(n \geq 5)$. $* p<0.05,{ }^{* *} p<0.01,{ }^{* * *} p<0.001$ versus untreated mice.

DCs expressing TLRs play an important role in triggering adaptive immunity to pathogens [53]. Recent studies have demonstrated that administering a TLR3 agonist enhanced the maturation of $C D 8 \mathrm{a}^{+}$ DCs, which in turn promoted cross-presentation in the tumor microenvironment and tumor regression $[54,55]$. Concurring with these findings, cHBV vaccination upregulated the expression of CD40, CD80, and CD86 on mDCs and pDCs. Moreover, pDCs exhibited stronger activation than mDCs upon treatment with the cHBV-vaccine, mainly due to the presence of $\mathrm{CpG}$ M362. In addition, $\mathrm{cHBV}$ vaccination decreased PD-L1 expression on hepatocytes, which is pivotal to the progressive loss of HBV-specific T cell function during $\mathrm{CHB}$ infection and has been shown to affect treatment response in later clinical therapy [5, 56]. Furthermore, mice administered the cHBV-vaccine exhibited significantly reduced Treg cell frequency and lower serum TGF- $\beta 1$ levels compared to untreated mice. Meanwhile, both HBsAg and HBV DNA levels were nearly undetectable in the vaccinated mice during the long-term memory immune response assay on day 66, accompanied with higher levels of protective anti-HBs. Taken together, these results indicate that $\mathrm{CHBV}$ vaccination inhibits CHB-induced immune tolerance and triggers long-term anti-HBV-specific immunity in HBV-carrier mice. Furthermore, the results support that treatment with rHBVvac alone does not efficiently eliminate $\mathrm{HBV}$, nor induce the same immunological effects as those induced by the $\mathrm{CHBV}$-vaccine.

Effector $\mathrm{CD}^{+} \mathrm{T}$ cells predict the efficacy of therapeutic vaccines against pathogens. However, CHB infection inhibits HBV-specific T cell responses, resulting in exhausted phenotypes, poor cytotoxic activity, and impaired cytokine secretion, accompanied by the expression of co-inhibitory receptors such as PD-1, LAG-3, CTLA-4, TIGIT, and TIM-3 [5, 39]. Blockade of PD-1 reportedly improved the proliferation of $\mathrm{CD}^{+} \mathrm{T}$ cells and increased production of IFN- $\gamma$ and IL-2, offering a novel therapeutic strategy for CHB [57-59]. Interestingly, the cHBV-vaccine also downregulated the expression of LAG-3, CTLA-4, TIGIT, and PD-1 immune checkpoints on $\mathrm{HBV}$-specific $\mathrm{CD}^{+} \mathrm{T}$ cells.

Antigen-experienced CD8 ${ }^{+} \mathrm{T}$ cells after infection or vaccination exhibit upregulated expression of CD11a and downregulated expression of CD8a on $\mathrm{CD}^{+} \mathrm{T}$ cells, whereas inflammatory stimulation alone, such as $\mathrm{CpG}$ administration, does not drive these changes [40]. During $\mathrm{CHB}$ infection, $\mathrm{HBV}$-specific $\mathrm{CD}^{+} \mathrm{T}$ cells are known to gradually lose effector functions, proliferative capacity, and cytolytic activity, in that order $[5,56]$. In the current study, cHBV vaccination increased the abundance of CD11a ${ }^{\text {hi }}$ CD8 $^{\text {lo }}$ cells, as well as the proliferative capacity and activation of $\mathrm{HBV}$-specific $\mathrm{CD}^{+} \mathrm{T}$ cells. Furthermore, cHBV-vaccinated mice exhibited significantly increased serum levels of IFN- $\gamma$ without elevated ALT levels, which concurred with previous studies reporting that IFN- $\gamma$ mediates non-cytolytic clearance of $\mathrm{HBV}$ from hepatocytes without liver damage $[5,60]$. Therefore, the therapeutic effects of the cHBV-vaccine are likely mediated via a non-cytolytic HBV CD8 ${ }^{+}$T cell effect.

Follicular CXCR5-expressing CD8 ${ }^{+} \mathrm{T}$ cells are a major reservoir of long-term immunity [24, 61]. Compared to the CXCR5- subset, CXCR5 ${ }^{+} \mathrm{CD}^{+} \mathrm{T}$ cells are localized to the splenic B cell follicles and tend to display an exhausted phenotype, expressing intermediate levels of PD-1 and TIGIT. In addition, they have enhanced effector potential, self-renewal capacity, and are negatively correlated with HBV progression [27, 61]. HBV-specific CD11a ${ }^{\text {hi }}$ CD8a ${ }^{\text {lo }}$ cells in the spleens of HBV-carrier mice abundantly expressed CXCR5, and were the predominant subset among exhausted cells. However, cHBV vaccination significantly reduced the expression of multiple co-inhibitory receptors on CXCR5 ${ }^{+} \mathrm{CD} 11 \mathrm{a}^{\text {hi }} \mathrm{CD} 8 \mathrm{a}^{\text {lo }}$ cells, indicating that $\mathrm{HBV}$ was eliminated by restoring exhausted $\mathrm{CXCR}^{+} \mathrm{HBV}$-specific $\mathrm{CD}^{+} \mathrm{T}$ cells. 
Effector $\mathrm{CD}^{+} \mathrm{T}$ cells also participate in humoral and cellular immune responses by generating and maintaining both neutralizing antibodies and $\mathrm{CD} 8^{+} \mathrm{T}$ cells to facilitate HBV clearance [62, 63]. Moreover, antigen-specific $\mathrm{CD}^{+} \mathrm{T}$ cells reportedly display CD11a ${ }^{\text {hi }}$ CD $49 \mathrm{~d}^{+}$surface marker expression [41]. Thus, cHBV vaccination increased the generation and activation of $\mathrm{HBV}$-specific $\mathrm{CD}^{+} \mathrm{T}$ cells, indicating that $\mathrm{CD} 4^{+} \mathrm{T}$ cells might contribute to the humoral and $\mathrm{CD} 8{ }^{+} \mathrm{T}$ cell response. Combined, these results suggest that augmented $\mathrm{HBV}$-specific $\mathrm{CD}^{+}$and $\mathrm{CD}^{+}{ }^{+} \mathrm{T}$-cell responses induced by the $\mathrm{cHBV}$-vaccine contribute to the elimination of HBV. Moreover, effective vaccines against viruses should generate a stable high-quality population of memory $\mathrm{CD}^{+} \mathrm{T}$ cells to confer long-term protective immunity [43, 46, 47, 64]. The abundance of HBV-specific CD11a ${ }^{\text {hi }}$ CD8 $a^{\text {lo }}$ cells, which were predominantly CXCR5 ${ }^{+} \mathrm{CD} 11 \mathrm{a}^{\text {hi }} \mathrm{CD} 8 \mathrm{a}^{\text {lo }} \mathrm{T}$ cells, increased remarkably after HBV re-challenge in cHBV-vaccinated mice, suggesting the cHBV-vaccine promoted a long-term memory response against the virus in HBV-carrier mice, accompanied by higher levels of protective anti-HBs.

In conclusion, CpG ODNs have been widely used as adjuvants for cancer and antiviral vaccines, such as CpG 1018 (CpG-B ODN) in HEPLISAV-B [14-18]. Moreover, a dose of spike (S)-protein (S-Trimer) combined with CpG 1018/Alum adjuvants induced robust humoral and cellular immune responses against SARS-CoV-2 in a phase II/III trial $[65,66]$. In the current study, the CpG M362-based $\mathrm{HBV}$ vaccine overcame systemic immune tolerance in HBV-carrier mice and restored exhausted HBV-specific $C D 8^{+} \mathrm{T}$ cells, which were predominantly $\mathrm{CXCR}^{+} \mathrm{CD} 11 \mathrm{a}^{\text {hi }} \mathrm{CD} 8 \mathrm{a}^{\text {lo }} \mathrm{T}$ cells. More importantly, this approach effectively induced long-term immune memory against HBV recurrence. Considering that CpG M362 combines the features of both class A and B CpG ODNs, the cHBV-vaccine provides a promising candidate for anti-HBV immunotherapy and the prevention of HBV.
A

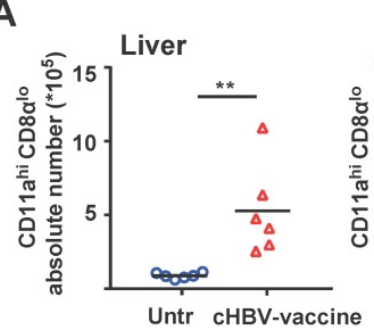

C

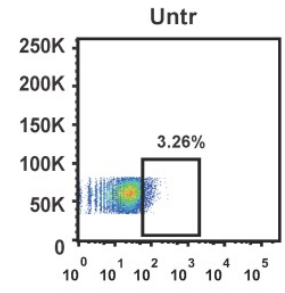

D
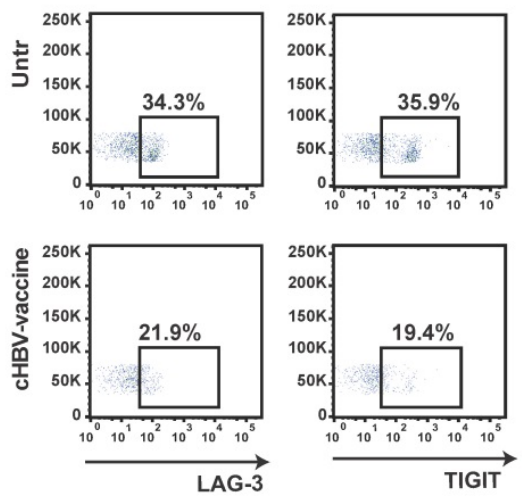

B

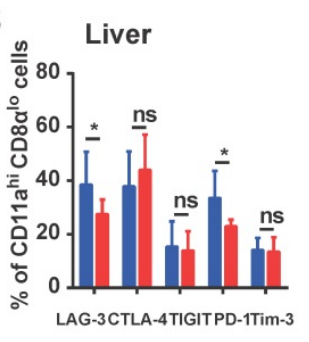

Spleen

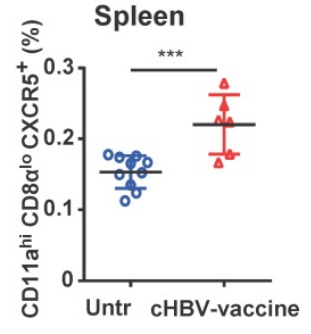

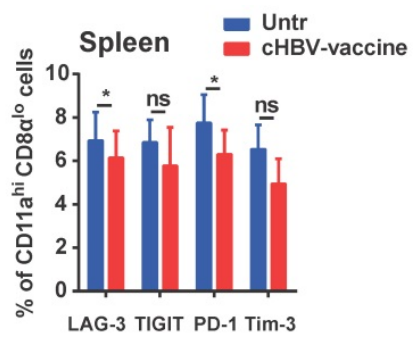
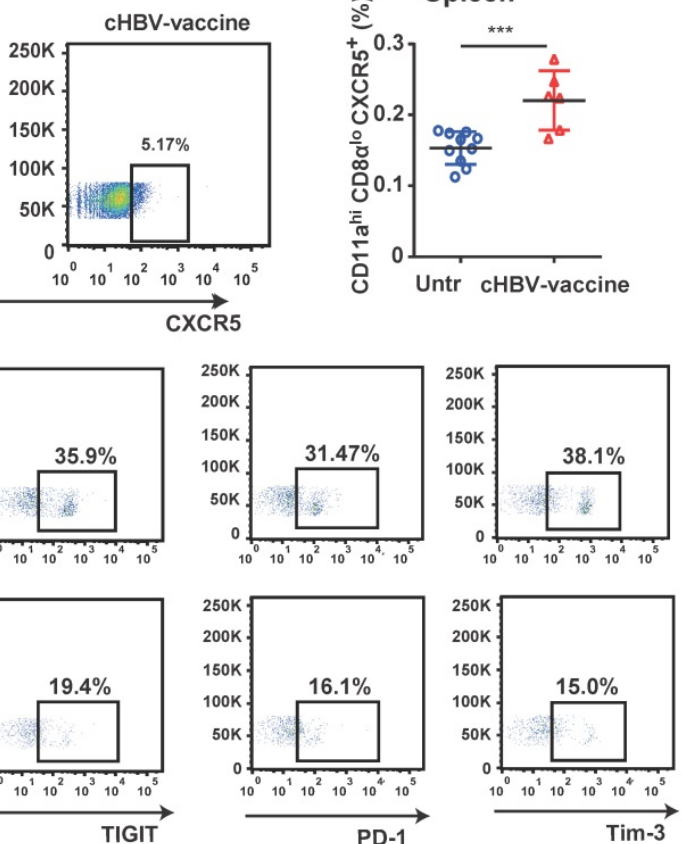
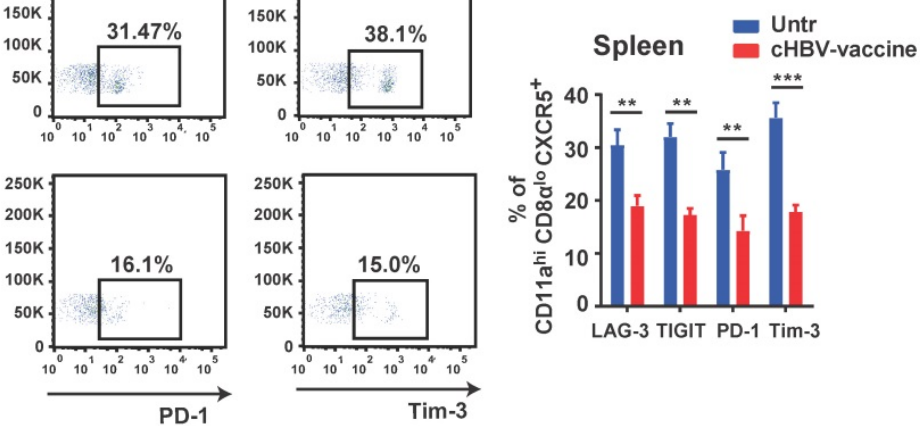

Figure 6. cHBV-vaccine induced long-lasting CXCR5+ CD8+ $\mathbf{T}$ cell response during $\mathbf{H B V}$ re-challenge. HBV-carrier mice were immunized subcutaneously with PBS (Untr) and $2 \mu \mathrm{g} \mathrm{rHBVvac}$ combined with $10 \mu \mathrm{g}$ CpG M362 (cHBV-vaccine) weekly for 3 weeks, separately. Then, these treated mice were re-challenged with hydrodynamic injection of $8 \mu \mathrm{g}$ PAAV/HBV1.2 plasmid on day 59 after the first vaccination. (A) Abundance of CDI la $\mathrm{a}^{\text {hi }} \mathrm{CD} 8 \alpha^{\mathrm{lo}}$ cells among CD8 ${ }^{+} \mathrm{T}$ cells from liver and spleen on day 7 after HBV re-challenge. (B) LAG-3, CTLA-4, TIGIT, PD-1 and Tim-3 expression on HBV-specific CDI la hi $^{\text {hi }}$ CD8 $\alpha^{\text {lo }}$ cells in liver (left) and spleen (right) on day 7 after HBV re-challenge. (C)

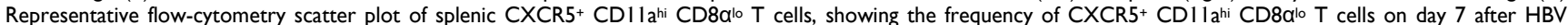
re-challenge. (D) Representative flow-cytometry scatter plot of PD-1, TIGIT, Tim-3, and LAG-3 expression on HBV-specific CXCR5 ${ }^{+}$CDI la hi CD8alo T cells on day 7 after HBV re-challenge. $* p<0.05, * * p<0.01, * * * p<0.001$ versus untreated mice. 


\section{Abbreviations}

anti-HBs: hepatitis B surface antibody; APCs: antigen-presenting cells; BMDCs: bone marrow-derived dendritic cells; CHB: chronic hepatitis B virus; CpG: cysteine-guanine dinucleotide; CTLA-4: cytotoxic T-lymphocyte-associated antigen-4; DCs: dendritic cells; dLNs: draining lymph nodes; HBV: hepatitis B virus; HBsAg: hepatitis B surface antigen; $\mathrm{HCV}$ : hepatitis $\mathrm{C}$ virus; HIV: human immunodeficiency virus; IFN- $\gamma$ : interferon- $\gamma$; IL-12: interleukin-12; $\mathrm{mAB}$ : monoclonal antibody; mDCs: myeloid dendritic cells; MNCs: mononuclear cells; ODN: oligodeoxynucleotide; PD-1: programmed cell death-1; pDCs: plasmacytoid dendritic cells; PD-L1: programmed death-ligand 1; RBC: red blood cell; Th1: $\mathrm{T}$ helper 1 cell; Tfh: follicular helper T cell; TIM-3: T-cell immunoglobulin domain and mucin domain 3; TNF- $\alpha$ : tumor necrosis factor- $\alpha$; Treg: regulatory $\mathrm{T}$ cell.

\section{Supplementary Material}

Supplementary figures. https://www.ijbs.com/v18p0154s1.pdf

\section{Acknowledgments}

This work was supported by grants from the National Postdoctoral Programme for Innovative Talents (No. BX20190192), China Postdoctoral Science Foundation (No. 2020M672064), the National Science Foundation for Young Scientists of China (No. 82001687), and the National Basic Research Programme of China (No. 2013CB531503). We thank the Pharmaceutical Biology Sharing Platform of Shandong University.

\section{Author Contributions}

JZ and HZ conceived the study, designed, and performed most of the experiments. HZ and GW analyzed the data. QH, AY, YW, GW, AL, XW and CY helped with performed the various experiments. JZ and HZ wrote the manuscript. All authors critically read and approved the final manuscript.

\section{Competing Interests}

The authors have declared that no competing interest exists.

\section{References}

1. Ott JJ, Stevens GA, Groeger J, Wiersma ST. Global epidemiology of hepatitis B virus infection: new estimates of age-specific HBsAg seroprevalence and endemicity. Vaccine. 2012;30:2212-2219.

2. Global Burden of Disease Liver Cancer C, Akinyemiju T, Abera S, et al. The Burden of Primary Liver Cancer and Underlying Etiologies From 1990 to 2015 at the Global, Regional, and National Level: Results From the Global Burden of Disease Study 2015. JAMA Oncol. 2017;3:1683-1691.

3. Sundaram V, Kowdley K. Management of chronic hepatitis B infection. BMJ. 2015;351:h4263.
4. Michel ML, Deng Q, Mancini-Bourgine M. Therapeutic vaccines and immune-based therapies for the treatment of chronic hepatitis B: perspectives and challenges. J Hepatol. 2011;54:1286-1296.

5. Shih C, Chou SF, Yang CC, Huang JY, Choijilsuren G, Jhou RS. Control and Eradication Strategies of Hepatitis B Virus. Trends Microbiol. 2016;24:739-749.

6. Bertoletti A, Kennedy PT. The immune tolerant phase of chronic HBV infection: new perspectives on an old concept. Cell Mol Immunol. 2015;12:258-263

7. Guidotti LG, Isogawa M, Chisari FV. Host-virus interactions in hepatitis B virus infection. Curr Opin Immunol. 2015;36:61-66.

8. Aillot L, Bonnin M, Ait-Goughoulte $\mathrm{M}$, et al. Interaction between Toll-Like Receptor 9-CpG Oligodeoxynucleotides and Hepatitis B Virus Virions Leads to Entry Inhibition in Hepatocytes and Reduction of Alpha Interferon Production by Plasmacytoid Dendritic Cells. Antimicrob Agents Chemother. 2018;62:e01741-17.

9. Krug A, Rothenfusser S, Hornung V, et al. Identification of CpG oligonucleotide sequences with high induction of IFN-alpha/beta in plasmacytoid dendritic cells. Eur J Immunol. 2001;31:2154-2163.

10. Verthelyi D, Ishii KJ, Gursel M, Takeshita F, Klinman DM. Human peripheral blood cells differentially recognize and respond to two distinct CPG motifs. J Immunol. 2001;166:2372-2377.

11. Vollmer J, Krieg AM. Immunotherapeutic applications of CpG oligodeoxynucleotide TLR9 agonists. Adv Drug Deliv Rev. 2009;61:195-204.

12. Hartmann G, Krieg AM. Mechanism and function of a newly identified CpG DNA motif in human primary B cells. J Immunol. 2000;164:944-953.

13. Hartmann G, Battiany J, Poeck H, et al. Rational design of new CpG oligonucleotides that combine B cell activation with high IFN-alpha induction in plasmacytoid dendritic cells. Eur J Immunol. 2003;33:1633-1641.

14. Malaspina A, Moir S, DiPoto AC, et al. CpG oligonucleotides enhance proliferative and effector responses of B Cells in HIV-infected individuals. J Immunol. 2008;181:1199-1206.

15. McHutchison JG, Bacon BR, Gordon SC, et al. Phase 1B, randomized, double-blind, dose-escalation trial of CPG 10101 in patients with chronic hepatitis C virus. Hepatology. 2007;46:1341-1349.

16. Siegrist CA, Pihlgren $\mathrm{M}$, Tougne $\mathrm{C}$, et al. Co-administration of CpG oligonucleotides enhances the late affinity maturation process of human anti-hepatitis B vaccine response. Vaccine. 2004;23:615-622.

17. Halperin SA, Ward $B$, Cooper $C$, et al. Comparison of safety and immunogenicity of two doses of investigational hepatitis $B$ virus surface antigen co-administered with an immunostimulatory phosphorothioate oligodeoxyribonucleotide and three doses of a licensed hepatitis B vaccine in healthy adults 18-55 years of age. Vaccine. 2012;30:2556-2563.

18. Lee GH, Lim SG. CpG-Adjuvanted Hepatitis B Vaccine (HEPLISAV-B(R)) Update. Expert Rev Vaccines. 2021;20:487-495.

19. $\mathrm{Hu} \mathrm{W}$, Huang $\mathrm{H}$, Zhang TY, Mao YY, Wang XJ, Wang SQ. CpG oligodeoxynucleotide inhibits HBV replication in a hydrodynamic injection murine model. Antivir Ther. 2015;20:289-295.

20. Isogawa M, Robek MD, Furuichi Y, Chisari FV. Toll-like receptor signaling inhibits hepatitis B virus replication in vivo. J Virol. 2005;79:7269-7272.

21. Lv S, Wang J, Dou S, et al. Nanoparticles encapsulating hepatitis B virus cytosine-phosphate-guanosine induce therapeutic immunity against HBV infection. Hepatology 2014;59:385-394.

22. Vibholm L, Schleimann MH, Hojen JF, et al. Short-Course Toll-Like Receptor 9 Agonist Treatment Impacts Innate Immunity and Plasma Viremia in Individuals With Human Immunodeficiency Virus Infection. Clin Infect Dis. 2017;64:1686-1695.

23. Frank MJ, Reagan PM, Bartlett NL, et al. In Situ Vaccination with a TLR9 Agonist and Local Low-Dose Radiation Induces Systemic Responses in Untreated Indolent Lymphoma. Cancer Discov. 2018:8:1258-1269.

24. He R, Hou S, Liu C, et al. Follicular CXCR5- expressing CD8(+) T cells curtail chronic viral infection. Nature. 2016;537:412-428.

25. Perdomo-Celis F, Taborda NA, Rugeles MT. Follicular CD8(+) T Cells: Origin Function and Importance during HIV Infection. Front Immunol. 2017;8:1241.

26. Leong YA, Chen Y, Ong HS, et al. CXCR5(+) follicular cytotoxic T cells control viral infection in B cell follicles. Nat Immunol. 2016;17:1187-1196.

27. Li Y, Tang L, Guo L, et al. CXCL13-mediated recruitment of intrahepatic CXCR5(+)CD8(+) T cells favors viral control in chronic HBV infection. J Hepatol. 2020;72:420-430.

28. Quigley MF, Gonzalez VD, Granath A, Andersson J, Sandberg JK. CXCR5+ CCR7- CD8 T cells are early effector memory cells that infiltrate tonsil B cell follicles. Eur J Immunol. 2007;37:3352-3362.

29. Yang $\mathrm{M}, \mathrm{Lu} J$, Zhang $\mathrm{G}$, et al. CXCL13 shapes immunoactive tumor microenvironment and enhances the efficacy of PD-1 checkpoint blockade in high-grade serous ovarian cancer. J Immunother Cancer. 2021;9:e001136. .

30. Tirosh I, Izar B, Prakadan SM, et al. Dissecting the multicellular ecosystem of metastatic melanoma by single-cell RNA-seq. Science. 2016:352-189-196.

31. Bian $Y$, Zhang Z, Sun Z, et al. Vaccines targeting preS1 domain overcome immune tolerance in hepatitis $B$ virus carrier mice. Hepatology. 2017;66:1067-1082.

32. Huang LR, Wu HL, Chen PJ, Chen DS. An immunocompetent mouse model for the tolerance of human chronic hepatitis B virus infection. Proc Natl Acad Sci U S A. 2006;103:17862-17867.

33. Xu L, Yin W, Sun R, Wei H, Tian Z. Liver type I regulatory $\mathrm{T}$ cells suppress germinal center formation in HBV-tolerant mice. Proc Natl Acad Sci U S A. 2013;110:16993-16998. 
34. Zhang TY, Yuan Q, Zhao JH, et al. Prolonged suppression of HBV in mice by a novel antibody that targets a unique epitope on hepatitis B surface antigen. Gut. 2016;65:658-671.

35. Zeng Z, Kong X, Li F, Wei H, Sun R, Tian Z. IL-12-based vaccination therapy reverses liver-induced systemic tolerance in a mouse model of hepatitis $B$ virus carrier. J Immunol. 2013;191:4184-4193.

36. Zhao HJ, Han QJ, Wang G, et al. Poly I:C-based rHBVvac therapeutic vaccine eliminates $\mathrm{HBV}$ via generation of $\mathrm{HBV}$-specific CD8(+) effector memory $\mathrm{T}$ cells. Gut. 2019;68:2032-2043.

37. Zhao H, Wang $\mathrm{H}, \mathrm{Hu} \mathrm{Y}$, et al. Chitosan Nanovaccines as Efficient Carrier Adjuvant System for IL-12 with Enhanced Protection Against HBV. Int J Nanomedicine. 2021;16:4913-4928.

38. Gehring AJ, Ann D'Angelo J. Dissecting the dendritic cell controversy in chronic hepatitis B virus infection. Cell Mol Immunol. 2015;12:283-291.

39. Wherry EJ. T cell exhaustion. Nat Immunol. 2011;12:492-499.

40. Rai D, Pham NL, Harty JT, Badovinac VP. Tracking the total CD8 T cell response to infection reveals substantial discordance in magnitude and kinetics between inbred and outbred hosts. J Immunol. 2009;183:7672-7681.

41. McDermott DS, Varga SM. Quantifying antigen-specific CD4 T cells during a viral infection: CD4 T cell responses are larger than we think. J Immunol. 2011;187:5568-5576.

42. Anderson AC, Joller N, Kuchroo VK. Lag-3, Tim-3, and TIGIT: Co-inhibitory Receptors with Specialized Functions in Immune Regulation. Immunity. 2016:44:989-1004.

43. Avdicova M, Crasta PD, Hardt K, Kovac M. Lasting immune memory against hepatitis $\mathrm{B}$ following challenge 10-11 years after primary vaccination with either three doses of hexavalent DTPa-HBV-IPV/Hib or monovalent hepatitis $B$ vaccine at 3, 5 and 11-12 months of age. Vaccine. 2015;33:2727-2733.

44. Gane EJ, Angus PW, Strasser S, et al. Lamivudine plus low-dose hepatitis B immunoglobulin to prevent recurrent hepatitis B following liver transplantation. Gastroenterology. 2007;132:931-937.

45. Kaech SM, Cui W. Transcriptional control of effector and memory CD8+ T cell differentiation. Nat Rev Immunol. 2012;12:749-761.

46. Olson JA, McDonald-Hyman C, Jameson SC, Hamilton SE. Effector-like $\mathrm{CD} 8(+) \mathrm{T}$ cells in the memory population mediate potent protective immunity. Immunity. 2013;38:1250-1260.

47. Ye F, Turner J, Flano E. Contribution of pulmonary KLRG1(high) and KLRG1(low) CD8 T cells to effector and memory responses during influenza virus infection. J Immunol. 2012;189:5206-5211.

48. European Association For The Study Of The L. EASL clinical practice guidelines: Management of chronic hepatitis B virus infection. J Hepatol. 2012;57:167-185.

49. Kobiyama K, Aoshi T, Narita H, et al. Nonagonistic Dectin-1 ligand transforms CpG into a multitask nanoparticulate TLR9 agonist. Proc Natl Acad Sci U S A. 2014;111:3086-3091.

50. Temizoz B, Kuroda E, Ohata K, et al. TLR9 and STING agonists synergistically induce innate and adaptive type-II IFN. Eur J Immunol. 2015;45:1159-1169.

51. Ma Z, Cao Q, Xiong Y, Zhang E, Lu M. Interaction between Hepatitis B Virus and Toll-Like Receptors: Current Status and Potential Therapeutic Use for Chronic Hepatitis B. Vaccines (Basel). 2018;6:6.

52. Wu J, Meng $Z$, Jiang $M$, et al. Hepatitis $B$ virus suppresses toll-like receptor-mediated innate immune responses in murine parenchymal and nonparenchymal liver cells. Hepatology. 2009;49:1132-1140.

53. Walsh KP, Mills KH. Dendritic cells and other innate determinants of Thelper cell polarisation. Trends Immunol. 2013;34:521-530.

54. Azuma M, Ebihara T, Oshiumi H, Matsumoto M, Seya T. Cross-priming for antitumor CTL induced by soluble Ag + polyI:C depends on the TICAM-1 pathway in mouse CD11c(+)/CD8alpha(+) dendritic cells. Oncoimmunology. 2012;1:581-592.

55. Azuma M, Takeda Y, Nakajima H, et al. Biphasic function of TLR3 adjuvant on tumor and spleen dendritic cells promotes tumor $\mathrm{T}$ cell infiltration and regression in a vaccine therapy. Oncoimmunology. 2016;5:e1188244.

56. Ye B, Liu X, Li X, Kong H, Tian L, Chen Y. T-cell exhaustion in chronic hepatitis B infection: current knowledge and clinical significance. Cell Death Dis. 2015;6:e1694.

57. Cox MA, Nechanitzky R, Mak TW. Check point inhibitors as therapies for infectious diseases. Curr Opin Immunol. 2017;48:61-67.

58. Fisicaro P, Valdatta C, Massari M, et al. Antiviral intrahepatic T-cell responses can be restored by blocking programmed death-1 pathway in chronic hepatitis B. Gastroenterology. 2010;138:682-693, 693 e681-684.

59. Fisicaro P, Valdatta C, Massari M, et al. Combined blockade of programmed death-1 and activation of CD137 increase responses of human liver T cells against HBV, but not HCV. Gastroenterology. 2012;143:1576-1585 e1574.

60. Wang X, Dong A, Xiao J, et al. Overcoming HBV immune tolerance to eliminate HBsAg-positive hepatocytes via pre-administration of GM-CSF as a novel adjuvant for a hepatitis $\mathrm{B}$ vaccine in $\mathrm{HBV}$ transgenic mice. Cell Mol Immunol. 2016;13:850-861.

61. Brummelman J, Mazza EMC, Alvisi G, et al. High-dimensional single cell analysis identifies stem-like cytotoxic CD8(+) T cells infiltrating human tumors. J Exp Med. 2018;215:2520-2535.

62. Chisari FV, Ferrari C. Hepatitis B virus immunopathogenesis. Annu Rev Immunol. 1995;13:29-60.

63. Zhu D, Liu L, Yang D, et al. Clearing Persistent Extracellular Antigen of Hepatitis B Virus: An Immunomodulatory Strategy To Reverse Tolerance for an Effective Therapeutic Vaccination. J Immunol. 2016;196:3079-3087.
64. Panagioti E, Redeker A, van Duikeren S, et al. The Breadth of Synthetic Long Peptide Vaccine-Induced CD8+ T Cell Responses Determines the Efficacy against Mouse Cytomegalovirus Infection. PLoS Pathog. 2016;12:e1005895.

65. Richmond PC, Hatchuel L, Pacciarini F, et al. Persistence of the immune responses and cross-neutralizing activity with Variants of Concern following two doses of adjuvanted SCB-2019 COVID-19 vaccine. J Infect Dis. 2021.

66. Richmond P, Hatchuel L, Dong $\mathrm{M}$, et al. Safety and immunogenicity of S-Trimer (SCB-2019), a protein subunit vaccine candidate for COVID-19 in healthy adults: a phase 1, randomised, double-blind, placebo-controlled trial. Lancet. 2021;397:682-694. 